\title{
Kierkegaard subjectief voor een breder publiek
}

Geert Jan Blanken, Kierkegaard. Een inleiding in zijn leven en werk. Amsterdam, Ambo, 2012, 197 pp., € 19,95 ISBN 9789026324932

Danig overtuigd van het uitzonderlijk belang van zijn denkbeelden leefde Søren Kierkegaard (1813-1855) met het vermoeden dat de dag zou komen waarop zijn leven en zijn geschriften duchtig zouden worden bestudeerd. Zelf heeft hij dat vermoeden nooit bewaarheid zien worden. Zijn magistraal geschreven onderzoeken naar wat het betekent en wat men behoort te doen om waarlijk als 'individu' (of 'enkeling') te 'existeren', bereikten tijdens zijn leven nauwelijks geïnteresseerde lezers. De weinige tijdgenoten die hij toch kon bekoren, kwamen na lectuur meestal niet veel verder dan beoordelingen doorspekt met spot, onbegrip en misprijzen.

Ernstige aandacht en dito erkenning verwierf de bekendste Deense filosoof pas postuum, en dan vooral pas in de $20^{\text {ste }}$ eeuw. Toen kwam zijn existentie-denken geleidelijk aan in zwang bij intellectuelen buiten Denemarken, in de eerste plaats bij theologen en filosofen. De eerder bescheiden filosofische belangstelling voor Kierkegaard zorgde ervoor dat zijn gedachtegoed gestaag de weg kon vinden naar de canon van de westerse filosofie. Gerenommeerde denkers, gaande van Ludwig Wittgenstein, Martin Heidegger en Jean-Paul Sartre, tot meer recent Jacques Derrida, Jürgen Habermas en Slavoj Žižek, verdiepten zich in zijn werk en integreerden de daaruit opgedane ideeën in hun eigen filosofische opvattingen. Het gevolg is dat nogal wat belangrijke hedendaagse filosofische teksten, zoals bijvoorbeeld Sein und Zeit, L'être et le néant, Donner la mort en Die Zukunft der menschlichen Natur zijn stempel dragen, en dat hij vandaag de dag onder vakfilosofen wereldwijd kan rekenen op een aanzienlijke schare aan geïnteresseerden. Voor sommigen is hij niet minder dan een volwaardig partner in het

hedendaags filosofisch debat. ${ }^{1}$ Anderen gaan verder en zien in zijn denken de grootste hoop voor een grondige vernieuwing van dat debat. ${ }^{2}$

Waarschijnlijk zou onder deze vorm de hem alsnog toegekende aandacht Kierkegaard weinig genoegdoening hebben verschaft. In plaats van uit te groeien tot een boeiend studieobject voor slechts een select groepje (vak)filosofen, leek hij eerder te hopen op weerklank bij een bredere, maar vooral 'andere' groep mensen. Hoe dikwijls liep hij niet in de voetsporen van zijn leermeester Socrates, wanneer hij tijdens zijn dagelijkse wandelingen door Kopenhagen zich 
wendde tot de 'gewone' man en vrouw in de straat, het café of theaterzaal met de bedoeling met hen van gedachten te wisselen? Wellicht had hij in de eerste plaats elk van hén voor ogen, wanneer hij het in heel wat van zijn teksten had over "mijn dierbare lezer"3. Wellicht ook dat hij zijn socratische schrijversmissie alleen dan als geslaagd zou hebben beschouwd als zijn teksten door hén zouden worden gelezen en de erin verkondigde ideeën door hén zouden worden onderzocht.

Anno 2013, het jaar waarin Kierkegaards tweehonderdste geboortedag op diverse manieren wordt herdacht, stellen we vast dat de belangstellingsgolf die zich in de loop van de twintigste eeuw aanvankelijk ontrolde onder academische en andere filosofen, zich nu eindelijk ook op gang begint te trekken bij een veel breder publiek. In aanzienlijk wat landen lijken liefhebbers van Kierkegaard zich gelijktijdig in te zetten om diens oeuvre een bredere bekendheid te geven, zeker onder 'gewone' mensen. Ook binnen het Nederlands taalgebied zijn er aardig wat initiatieven die bijdragen tot een respectvolle vulgarisering. Het meest in het oog springende, want wellicht meest ambitieuze is het pionierswerk van de Redactieraad Kierkegaard Werken (RKW). Deze vereniging van Kierkegaard-deskundigen brengt sinds 2006 op geregelde tijdstippen accurate Nederlandse vertalingen van Kierkegaards geschriften uit. Zo verschenen kort na elkaar bekende titels als Vrees en beven, Het begrip angst, De ziekte tot de dood, ook enkele minder bekende religieuze opbouwende toespraken, en recentelijk nog een bundeling vroege dagboekfragmenten, in de verjaardaguitgave Een idee om voor te leven en te sterven. Tijdens dit herdenkingsjaar plant de RKW de publicatie van nog drie nieuwe vertalingen. Op termijn zal zo voor het eerst het bijna volledige oeuvre van de in het Deens schrijvende filosoof in het Nederlands te consulteren zijn.

Toch verschaffen vertalingen alleen geen voldoende garantie voor de verhoopte toename van het aantal Kierkegaard-lezers. Daarvoor zijn de gedachten van de 'vader van het existentialisme' te complex en stoten de stijl en de stroeve taal waarin ze zijn geformuleerd mogelijks op een te grote weerstand. Kierkegaard lezen vergt een groot doorzettingsvermogen, zelfs in de uitstekende RKW-vertalingen. Bij de meeste van zijn teksten staat de lectuur ervan gelijk aan het zich een moeizame weg banen door een met ongedefinieerde concepten bezaaid doolhof, daarbij geleid (of beter: 'misleid') door bevreemdende pseudoniemen, die dan bovendien nog eens kunnen gehuld zijn in een ingewikkeld hegeliaans jasje. 
Dit 'gedwongen-moeilijke-zoeken' maakt essentieel deel uit van elke authentieke 'Kierkegaard experience'. Kierkegaards uitdrukkelijke ambitie als schrijver was zijn lezers tot 'enkelingen', tot 'zelven' te activeren, door hen meer bepaald te ontregelen en perplex te laten staan, en hen vervolgens zonder enige vorm van externe leiding, een positie te laten innemen, allereerst tegenover het geschrevene, en uiteindelijk ook existentieel, tegenover hun eigen, persoonlijke leven. Kierkegaard drong via zijn teksten aan op engagement naar het eigen bestaan toe, maar gaf nauwelijks klare aanwijzingen over de daarvoor te bewandelen weg; hij schreef per slot van rekening "zonder autoriteit" 4 en liet het volledig aan de lezer zelf over om existentieel te 'springen'. Dat Kierkegaard-lezers - zeker de neofieten onder hen - als gevolg hiervan overmand kunnen worden door een gevoel van verlatenheid en ertoe overgaan definitief van verdere lectuur af te zien, is bijgevolg volkomen begrijpelijk.

Het nemen van zo'n radicale beslissing is evenwel nergens voor nodig. Wie zijn weg verliest in Kierkegaard kan zich immers makkelijk heroriënteren met behulp van de vele beschikbare introducties op zijn denken. Vooreerst zijn er natuurlijk deze van internationaal gerenommeerde Kierkegaard-kenners als Clare Carlisle (King's College London), John D. Caputo (Syracuse University en Villanova University) en M. Jamie Ferreira (University of Virginia). ${ }^{5}$ Maar binnen dezelfde vulgariseringbeweging waartoe de RKW-vertalingen behoren, verschenen de voorbije jaren voor een Nederlandstalige doelgroep gelijkaardige en even kwaliteitsvolle inleidingen. Volledig gewijd aan Kierkegaard is bijvoorbeeld de oorspronkelijk Engelstalige bijdrage van wijlen Patrick Gardiner (Magdalen College, Oxford) aan de uitmuntende Lemniscaat-reeks 'Kopstukken Filosofie'. ${ }^{6}$ Het boekje van Pieter Vos (Protestantse Theologische Universiteit), dat sleutelteksten van Kierkegaard thematisch combineert met overzichtelijk inleidend commentaar, mag als een even grote aanwinst worden beschouwd. ${ }^{7}$ Ook handig en inzichtelijk is de deskundige duiding in de vorm van een nawoord of essay die de RKW toevoegt aan elke door haar vertaalde tekst. Maar de ons inziens meest aanbevelenswaardige Nederlandstalige wegwijzer is toch wel het recent in de boekenrekken belande werkstuk van Geert Jan Blanken, getiteld Kierkegaard. Een inleiding in zijn leven en werk.

Blankens Kierkegaard-introductie is een opmerkelijk boek, niet in het minst omdat het geschreven is door een niet-academicus - Blanken schreef het bijeen na zijn professionele uren als programmamanager van de Nederlandse Evangelische Omroep. Het is een negen 
hoofdstukken tellend opstel, aantrekkelijk uitgegeven met op de cover een ongewoon, 'popart'achtig portret van de Deense denker. Het boek richt zich overduidelijk tot een ruim en niet noodzakelijk academisch of filosofisch geschoold publiek. Blanken slaagt er moeiteloos in de dikwijls moeilijk te doorgronden gedachten van Kierkegaard in een opvallend heldere taal, verstaanbaar weer te geven en ongecompliceerd toe te lichten. Blanken richt zijn verhelderende blik eerder thematisch dan chronologisch op Kierkegaards oeuvre en behandelt daaruit achtereenvolgens volgende belangrijke thema's: 'liefde' (hoofdstuk 2), 'angst' (hoofdstuk 3), 'vertwijfeling' (hoofdstuk 4), 'enkeling-zijn' (hoofdstuk 5), 'herhaling' en 'eeuwigheid' (allebei hoofdstuk 6), 'geloven als paradox' (hoofdstuk 7), 'zorgen' en 'lijden' (allebei hoofdstuk 8). Bij elk thema plaatst Blanken minstens één tekst van Kierkegaard in de schijnwerpers en telkens laat hij de lezer daaruit proeven door een ruim aanbod van goed gekozen, doch soms door hemzelf bewerkte citaten, overgenomen uit de reeds beschikbare Nederlandse vertalingen. Een doorgedreven tekstanalyse laat Blanken achterwege, maar de beginnende Kierkegaard-lezer verwerft wel een quasi compleet inhoudelijk overzicht van Kierkegaards oeuvre.

Een onbetwistbaar pluspunt is dat Blanken met elke verheldering Kierkegaard uitdrukkelijk vrijwaart van intellectueel onrecht: ofschoon verleidelijke valkuilen voor wie zich richt tot een breed publiek, kunnen we hem nergens in zijn boek betrappen op een verfoeilijk simplisme noch op een deformerende karikatuur. Wel integendeel, wanneer hij bijvoorbeeld in hoofdstuk 2 een bespreking wijdt aan Kierkegaards eerste gepubliceerde hoofdwerk $O f / O f$ en daarbij inzoomt op de drie door Kierkegaard veelvuldig gebruikte begrippen 'esthetisch', 'ethisch' en 'religieus', is het Blanken zélf die ons terecht waarschuwt voor sommige populariserende voorstellingen die deze begrippen al te simplistisch in het schematiserend keurslijf van een zogenaamde 'stadia'- of 'fasen'-theorie duwen. Als meest voor de hand liggend argument roept Blanken Kierkegaards alom gekende anti-hegeliaanse huiver voor abstrahering en systematisering in, vooral als het diens voornaamste reflectiegebied betreft, de praktijk van authentiek individueel in het leven staan.

Blanken springt dus voorzichtig en genuanceerd om met Kierkegaards concepten en geeft daarmee blijk van een groot respect voor diens ideeëngoed. Deze houding heeft hij onmiskenbaar gemeen met de auteurs van de andere vernoemde inleidingen. Toch is er tussen Blanken en hen op dat vlak een belangrijk verschilpunt: in zijn eerbied voor de Deense filosoof stelt Blanken zich ons inziens veel consequenter en verregaander op, meer in overeenstemming met Kierkegaards 
denken zelf. Wie immers de boeken van Carlisle, Caputo, Ferreira, Gardiner en Vos openslaat, krijgt een 'objectief' beeld van het leven en denken van Kierkegaard te zien. De ironie wil dat ze daarmee Kierkegaards ideeën in zekere zin geweld aandoen. Direct bepaald door hun positie als academicus lijken ze Kierkegaard te reduceren tot een interessant en vanuit ideeën-historisch oogpunt, waardevol studieobject dat ze met behulp van een arsenaal aan wetenschappelijke methodieken zo volledig en correct mogelijk trachten te beschrijven. Met die invalshoek komen ze elk ongeveer tot hetzelfde 'neutrale' basisrecept voor hun monografie: een toelichting van Kierkegaards levensloop; een belichting van zijn ambivalente verhouding tot de hegeliaanse filosofie; een uiteenzetting over de merkwaardige door hem gehanteerde communicatievorm van de 'indirecte mededeling'; nauwkeurige en tekstkritische samenvattingen van zijn geschriften, al dan niet voorzien van relevante tekstpassages; en tot slot, handige appendices zoals biblio- en biografische lijstjes en overzichtjes. Voor de beginnende Kierkegaard-lezers vormt dergelijk informatief geheel zeker een vertrouwenwekkende gids, één waarmee ze zonder twijfel in staat zijn zelfstandig Kierkegaards teksten te lijf gaan. Ook Blanken bezorgt hen deze instructieve ondersteuning, want ook hij neemt grotendeels bovenstaande objectieve receptuur over. Maar het originele bij hem is dat hij die aanwendt op een manier waarbij hij ze uittilt boven de objectiviteit, naar de door Kierkegaard zelf hoger gewaardeerde 'subjectiviteit', en dat is iets wat volledig ontbreekt bij Carlisle en co.

Over het concept 'subjectiviteit' bij Kierkegaard zijn al honderden academische pagina's bijeen geschreven. Het is een van zijn bekendste motieven. We vinden het uitvoerig behandeld in zijn indrukwekkend Afsluitend Onwetenschappelijk Naschrift op Filosofische Fragmenten. Daarin poneerde hij bij monde van het pseudoniem Johannes Climacus dat niet de objectiviteit maar de subjectiviteit de waarheid is. Ook maken we in dat nog steeds niet in het Nederlands vertaalde boek kennis met het ideaal van de zogenaamde 'subjectieve denker'. Kierkegaard achtte de subjectiviteit belangrijk omdat in tegenstelling tot de objectiviteit deze houding geen abstractie makt van de concreet existerende persoon in zijn existentie: zo zijn subjectieve waarheden, waarheden die niet louter door het subject 'gekend' worden, maar die vooral existentieel toegeëigend en dus concreet 'geleefd' worden; "zichzelf begrijpen in de existentie"8 is dan weer de voornaamste taak van de subjectieve denker.

Hoe belangrijk ook voor Kierkegaard, het valt op dat Blanken nauwelijks een alinea besteedt aan deze sleutelopvattingen. Wat op het eerste gezicht kan doorgaan voor een ernstige 
lacune is dat na een grondige lezing van zijn boek zeker en vast niet: in plaats van te opteren voor een objectieve beschrijving van Kierkegaards ideeën over 'subjectiviteit' neemt Blanken de weg van de praktische illustratie door zich doorheen gans zijn tekst onomwonden 'subjectief' op te stellen en zich meer bepaald 'subjectief' te verhouden tot diens gedachten, én te benadrukken in welke mate die gedachten bijdragen tot een beter inzicht ín en omgang mét ons bestaan.

Reeds vanaf het inleidend hoofdstuk typeert hij Kierkegaard zoals wij hem eerder in deze boekbespreking ook kenschetsten: als een schrijver die bij zijn lezers een existentiële transformatie richting 'zelfwording' wenste teweeg te brengen, als een publicist die anderen op allerlei ingenieuze manieren wilde uitnodigen met volle overgave 'voorwaarts te leven', opdat men niet van zichzelf en de wereld zou vervreemden. Blankens betoog is volledig opgehangen aan deze typering, ongetwijfeld omdat hij zelf Kierkegaard zo heeft gelezen en ervaren. Ogenschijnlijk vanuit persoonlijke ondervinding stelt hij: "Kierkegaard heeft veel, heel veel te bieden in termen van toepasbare, praktische wijsheid" (p. 13), en enkele pagina's verder beveelt hij de filosoof zelfs aan aan "degenen die zich wél met grote regelmaat afvragen wie ze zijn en daarin vaak genoeg vermoeid vastlopen. Degenen die misschien wel hyperreflectief zijn en vol enerzijds-anderzijdsgedachten eindeloos variaties zoeken op wat uiteindelijk toch weer hetzelfde rondje blijkt. Juist diegenen", vervolgt Blanken, "konden weleens aangenaam verrast worden door wat Kierkegaard te bieden heeft, want dat zijn degenen die in hem iemand treffen die zelf als geen ander diezelfde rondjes heeft gelopen" (p. 20).

In tegenstelling tot de 'objectieve' Kierkegaard-introducties schemert in Blankens boek en dit dus reeds van bij de aanvang - een duidelijk existentiële betrokkenheid met Kierkegaards filosofie door. Waarschijnlijk vond Blanken in de boeken 'van' Kierkegaard erg bevredigende antwoorden op tal van existentiële vragen en heeft hij met zijn boek 'over' Kierkegaard de Deense denker een forum willen geven zodat die ook Blankens lezers uiteindelijk zou kunnen inspireren. Het boek wil inderdaad zoveel mogelijk recht doen aan Kierkegaards initiële bedoeling, namelijk de lezer existentieel bewust maken en transformeren. Niet alleen geeft het in elk thematisch hoofdstuk een welbepaald aspect van Kierkegaards denken weer, ook zet het net als Kierkegaard zelf de lezer tegelijkertijd aan tot reflectie over existentiële twijfels die schuilgaan achter vragen als: wat is liefde? wanneer handel ik vrij? moet ik angst hebben voor de dood? of voor het leven? wanneer ben ik niet langer mezelf? zal ik doen wat de 'mensen' doen? hoe ga ik om met verveling? enzovoort. 
In zijn poging ons zo dicht mogelijk tot Kierkegaard te brengen, zet Blanken allerlei retorische middelen in. Zo kunnen Kierkegaards denkbeelden op elke pagina op volledige instemming rekenen; nooit trekt Blanken ze in twijfel, laat staan dat hij ze onderwerpt aan een kritische evaluatie. Ook trekt hij de grens tussen geparafraseerde weergave van Kierkegaards ideeën en eigen interpretatie niet altijd even duidelijk. Dikwijls, vooral in de hoofdstukken gewijd aan de proto-existentialistische teksten Het begrip angst en De ziekte tot de dood, neemt Blanken het bijna onopvallend over van Kierkegaard en redeneert hij verder in de lijn 'van' én ter ondersteuning 'van', maar niet noodzakelijk geheel 'volgens' Kierkegaard. Verder, als hij het bijvoorbeeld over de concepten 'angst' en 'vertwijfeling' heeft dan lijkt Blanken zich volledig te kunnen vinden in de psychologische beschrijvingen door Kierkegaard en herformuleert hij die op zo'n manier waardoor we als lezer de indruk krijgen dat Blanken het over zichzelf én zelfs over ons heeft (stelselmatig maakt hij gebruik van de tweede persoon enkelvoud en de eerste persoon meervoud). Een laatste manier waarmee Blanken affiniteit met Kierkegaard aanwakkert, is te verwijzen naar de relevantie van diens ideeën binnen de hedendaagse context van onder andere 'psychiatrisering' (zie hoofdstuk 3), massificatie en mediatisering (zie hoofdstuk 5) Kierkegaard inzetbaar om onszelf als $21^{\text {ste }}$ eeuwse individuen te begrijpen, menen we hier te denken.

Als conclusie van deze boekbespreking kunnen we opmerken dat het niet ondenkbaar is dat Blankens 'subjectieve' benadering ergernis kan opwekken bij gevorderde en vooral academische Kierkegaard-lezers. Voor hen is zijn boek evenwel niet bedoeld. Wel is het voor geïnteresseerden zonder uitgesproken voorkennis. Zij treffen met Blankens boek de tot nu toe meest op kierkegaardiaanse leest geschoeide Nederlandstalige inleiding tot Kierkegaard aan. Zij doen er dan ook goed aan even een omweggetje langs dat boek te maken alvorens zich volop te wagen aan de inspirerende boeken van het Deense genie zelf.

Kjell Bleys (UGent) 
Noten:

${ }^{1}$ Merold Westphal and Martin J. Matuštík, 'Introduction' in: Martin J. Matuštík and Merold Westphal (eds.), Kierkegaard in Post/Modernity, Bloomington and Indianapolis, Indiana University Press, 1995, p. vii.

${ }^{2}$ Roger Poole, 'The unknown Kierkegaard: Twentieth-century receptions' in: Alistair Hannay and Gordon D. Marino (eds.), The Cambridge Companion to Kierkegaard, Cambridge, Cambridge University Press, 1998, p. 72.

${ }^{3}$ Zie bijvoorbeeld: 'For Self-Examination' in: Søren Kierkegaard, The Essential Kierkegaard, ed. Howard V. Hong and Edna H. Hong, Princeton, Princeton University Press, 2000, p. 393.

${ }^{4}$ Søren Kierkegaard, The Point of View, ed. and transl. by Howard V. Hong and Edna H. Hong, Princeton, Princeton University Press, 2009, p. 12.

${ }^{5}$ Clare Carlisle, Kierkegaard. A Guide for the Perplexed, London, Continuum, 2006; John D. Caputo, How to read Kierkegaard, London, Granta Books, 2007; M. Jamie Ferreira, Kierkegaard, Oxford, Wiley-Blackwell, 2009.

${ }^{6}$ Patrick Gardiner, Kierkegaard, Rotterdam, Lemniscaat, 2001.

${ }^{7}$ Pieter Vos, Søren Kierkegaard lezen, Kampen, Kok, 2010.

${ }^{8}$ Søren Kierkegaard, Concluding Unscientific Postscript to Philosophical Fragments. Volume I: Text, ed. and transl. by Howard V. Hong and Edna H. Hong, Princeton, Princeton University Press, 1992, p. 351. 